\title{
Spotlight, de Thomas McCarthy (Dir)
}

Mario Arroyo Martínez Fabre*

p.marioa@gmail.com

Universidad de Piura

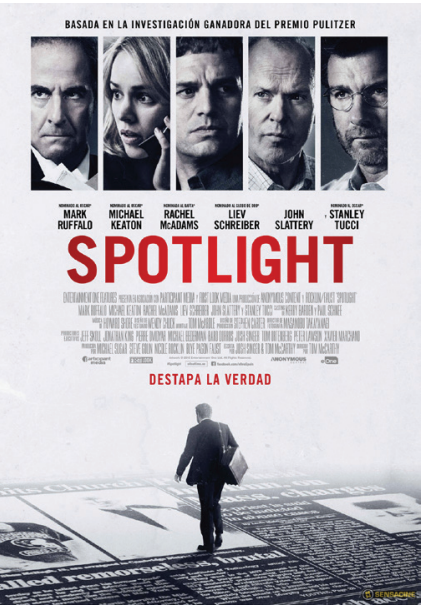

Spotlight

Director: Thomas McCarthy

Estados Unidos: Anonymous Content

Año: 2015, 2 h. y 9 min.

Potlight, filme nominado a seis Óscares, de los cuales finalmente ganó dos estatuillas $\circlearrowleft$ (Mejor película y Mejor guion original), relata una verdad incómoda para los católicos.

* Mario Arroyo Martínez Fabre es licenciado en Filosofía por la Universidad Panamericana (Ciudad de México, 1996); bachiller en Teología por la Pontificia Universidad de la Santa Cruz, (Roma, 1999) y doctor en Filosofía por la misma universidad (2002). Ordenado sacerdote en Torreciudad, España, en el 2002, ha desempeñado su ministerio sacerdotal en España, México, Perú y Ecuador. Ha sido capellán del Colegio Humtec, ubicado en el distrito de Comas, y del Centro Cultural Sama, en Santa Beatriz. Actualmente es capellán de la Universidad de Piura (Campus Lima). En el Perú, sus artículos han sido publicados a través del portal Lucidez.pe. De igual manera, publicó el libro Poder, Dinero y Santidad. Una aproximación desde la Doctrina Social de la Iglesia (Lima, 2012), Ciencia y fe: ¿un equilibrio posible? (Lima: Fondo Editorial UCSS, 2015) y Ciencia y Fe. Situación Actual (Lima, 2016). Es también coautor del libro Dios busca al hombre, (Lima, 2013). 
Nos recrea la apasionante investigación periodística que a principios del 2002 destapó los casos de pederastia cometidos por sacerdotes en Boston. A partir de allí, como una especie de epidemia maldita, fueron saliendo al aire, primero en Estados Unidos y después en muchos otros países del mundo, casos similares.

La película narra una sorprendente y triste realidad. Por un lado, expresa muy bien el asombro ante ese progresivo caer en la cuenta de las dimensiones del problema por parte del equipo de periodistas. Por el otro, muestra el demoledor impacto que supuso para la fe de varios de ellos, y para muchísimas personas, primero en Boston, pero a partir de allí en el mundo entero. Cuenta una triste verdad y lo hace notablemente.

Como sacerdote católico, lo confieso, pasé un mal rato al verla. Pienso, sin embargo, que aunque no nos agrade la verdad, esta es siempre un don de Dios, toda verdad viene de Dios. De hecho, no es descabellado pensar que también vino de Dios este terremoto que supuso para la Iglesia ventilar tan aberrante realidad. Por supuesto, ha sido muy bueno que saliera a la luz, pues en caso contrario, muy probablemente seguiría habiendo nuevas víctimas e impunidad para los criminales. Es impensable que esta dolorosa enfermedad permaneciera soterrada; evidenciarla ha sido necesario para iniciar la terapia de curación.

Ese es, a mi juicio, el valor y, al mismo tiempo, el límite de Spotlight. Cuenta la verdad, lo cual es muy importante, y para los católicos, fundamental, pues nos ayuda a tener una fe madura. Nuestra fe está en Cristo y en la asistencia del Espíritu Santo a su Iglesia, pero cada domingo rezamos el "Yo confieso", pues somos conscientes de ser pecadores. El límite es que no cuenta toda la verdad, y no hay que olvidar que "una verdad a medias es la peor mentira”, precisamente porque es verosímil, creíble. ¿Qué le falta contar a Spotlight? Lo que sucedió después. La película concluye con la crisis de fe que sufrieron los periodistas y el pueblo norteamericano, pero no dice lo que hizo la Iglesia, primero en este país y, siguiendo su ejemplo, en el resto del mundo, para erradicar el problema. No cuenta cómo después de esa dura prueba para la fe de los católicos norteamericanos, a catorce años de distancia, esa fe ha renacido más fuerte, no ha decaído la religiosidad de ese pueblo, sino que ahora es más madura y, por lo tanto, sobrenatural en sus motivos.

Hoy por hoy, uno de los lugares más seguros para dejar a los niños son las instituciones católicas norteamericanas. Además, el prestigio, también moral, de la Iglesia y sus pastores en ese mismo país se ha recuperado (como lo confirma el reciente viaje de Francisco). Spotlight está hecha, como cabe esperarse de un filme hollywoodense, para ganar premios, dinero y contar una historia. Pero si uno quiere conocer la historia completa, necesita de una 
segunda parte (lo que no es objetivo de la película ni de sus productores), que bien podría ser el documental Manzanas podridas de Rome Reports, el cual narra precisamente lo que sucedió después. En este se detalla la decidida lucha por sanear la institución, primero en E.E.U.U., y después en el resto de la Iglesia durante el pontificado de Benedicto XVI. Ello, claro está, es útil si uno desea tener la perspectiva completa, pues muchos prefieren quedarse con la visión parcial; no buscan la verdad sino justificar sus prejuicios.

La investigación, magistralmente escenificada en Spotlight, testimonia un cambio de paradigma en la Iglesia Católica. Produjo un proceso de maduración violento y fuerte para la institución, que debió adecuarse violentamente a los tiempos en que vivimos, caracterizados por el acceso irrestricto y en tiempo real a una gran cantidad de información. El reportaje funcionó como catalizador y empujó a la Iglesia a cambiar de política, a renovar su modus operandi. Pasó de intentar cuidar la imagen a toda costa — "para evitar escándalos”-, a promover la transparencia y la claridad en la información. El doloroso proceso comenzó con la investigación del Boston Globe, pero ha seguido a lo largo de estos años.

Es importante resaltar lo de "cambio de paradigma", pues, en caso contrario, no se habrá entendido en profundidad el mensaje del filme. ¿¿A qué me refiero? Por ejemplo, en un momento de la película Michael Rezendes (Mark Ruffalo) quiere publicar la información que han conseguido, pues está claro que ya están en grado de hundir al cardenal Law. Sin embargo Walter Robinson (Michael Keaton) no acepta, y se produce una dura discrepancia entre ambos. "Robby" se da cuenta de que no se trata del cardenal — sería lo más sencillo, encontrar un chivo expiatorio y cargarle toda la culpa - sino del sistema. En ese momento podían inculpar al cardenal, pero el sistema no estaba comprometido; "Robby" intuye que el problema tiene más trasfondo y prefiere ahondar en la investigación. El resultado es que no se trata de "un cardenal corrupto", sino de algo mucho peor, "de un sistema corrompido". Esto se evidencia porque a Boston le siguió una auténtica cadena de casos similares en Estados unidos y el mundo entero.

Entender esto puede ayudar a comprender no solo la película, sino también por qué no pasó nada con Bernard Law. Bastantes críticos de la Iglesia han puesto el dedo en la llaga al considerar que en realidad no se ha llegado a fondo en el tema, y la prueba de ello es Law. De alguna forma buscaban un chivo expiatorio o un castigo ejemplar que reparara la injusticia. Sin embargo, Law, relevado de su cargo en Boston, que obviamente era insostenible, fue enviado a Roma de forma sospechosa, pues dejaba suponer que, en realidad, huía de la justicia norteamericana. Más aún, Law fue "premiado" al ser nombrado 
arcipreste de la Basílica de Santa María la Mayor, lo cual equivalía a retirarlo airosamente de la escena, pues es un título más bien honorífico. Incluso, participó más tarde en la elección de Benedicto XVI y continuó como consultor de algunos dicasterios romanos hasta cumplir los ochenta años.

¿Por qué no fue castigado Law, encubridor de sacerdotes pederastas entre 1984 y 2002? No es fácil ofrecer una respuesta. La razón quizá estriba en que funcionó según aquel sistema vigente. El obispo es padre del sacerdote, y debe intentar su regeneración. La relación de confianza se rompe si se convierte en su acusador. El obispo debe velar también por el buen nombre de la Iglesia y evitar así todo escándalo, al resolver con discreción los eventuales puntos oscuros, inevitables en toda institución formada por hombres. Al fin y al cabo, "la ropa sucia se lava en casa". Así funcionaba la Iglesia hasta el 2002. Así, según el procedimiento entonces vigente, obró Law. Por eso, supongo, no fue castigado, sino simplemente quitado de en medio. A partir de allí comenzó el cambio de paradigma; los que posteriormente incurrieron en la misma falta no corrieron con la misma suerte.

La avalancha ocasionada por Spotlight obligó a la Iglesia a cambiar de estrategia. Le hizo tomar conciencia de que si el obispo es "padre" del sacerdote, con mucha mayor razón debe velar por los miembros más débiles de su feligresía, los niños, y que la defensa de los niños está por encima de cualquier buen nombre o noble deseo de regeneración sacerdotal. Por eso, Ana Sánchez de la Nieta puede afirmar con rotundidad: "Los grandes beneficiados del reportaje que publicó Spotlight fueron, en primer lugar, las víctimas y, en segundo lugar, la Iglesia Católica” (Sánchez de la Nieta, 2016, párr. 5). En efecto, ahora tiene una política de claridad y transparencia, y en este caso concreto, busca trabajar de la mano con la autoridad civil (la Iglesia puede quitar el estado clerical a un abusador, pero no condenarlo a la cárcel).

La Iglesia se ha adecuado, si bien traumáticamente, al actual mundo de la hiperinformación, con las ventajas que esto supone en lo que se refiere a claridad y transparencia. El hacerlo, a la postre, le ha venido muy bien, pues "a todas las instituciones, también a las religiosas, les viene de perlas comunicar y hacerlo bien. Es el mejor modo de fidelizar a los suyos, de hacerlos crecer y de ganar adeptos. Y un camino también para sanar, curar y terminar con lo que corrompe a las instituciones” (Sánchez de la Nieta, 2016, párr. 10). Reconocer con sencillez los errores y comenzar con humildad a corregirlos le ha devuelto la credibilidad a la institución. "La Iglesia ha entendido, quizás a golpes, que el gran problema es el pecado —en este caso, además, un delito- y no la publicación del 
pecado, y que, como primera medida, para terminar con un delito hay que sacarlo a la luz y denunciarlo” (Sánchez de la Nieta, 2016, párr. 10).

El mismo Mark Ruffalo (nominado al Óscar como Mejor actor de reparto), en una entrevista, reconoce que la investigación significó una oportunidad para que la Iglesia institucionalmente corrigiera su lamentable error, cosa que efectivamente hizo:

Veo esto como una oportunidad de la Iglesia para ganar credibilidad. Una de las cosas más tristes de esta película no son solo las víctimas, sino también las personas que han perdido su fe a causa de ver la forma en que la Iglesia se ha comportado. Eso es tan devastador en muchos aspectos. Esta es una maravillosa oportunidad para que la Iglesia comience a reparar el daño que han infligido a la gente. Para decir lo siento, para hacer justicia, para hacer lo que tienen que hacer y empezar a sanar la herida. ¡Y lo hicieron! ¡No fue culpa de los periodistas! Los periodistas hacen solo su trabajo. (“Mark Ruffalo: 'Tengo gran respeto por el periodismo',' 2016)

Trabajo muy valioso no sólo para hacer justicia a las víctimas, sino para que dentro de la Iglesia se tomara conciencia de la dimensión del problema. La sorpresa generada por Spotlight no fue solo para los feligreses y el mundo en general, sino para la misma jerarquía, comenzando con el papa san Juan Pablo II y, más tarde, con Benedicto XVI. El primero, durante el mismo año de la investigación (2002), llamó a los cardenales norteamericanos y les llamó duramente la atención por el mal manejo de la situación. A su vez, inició un proceso de reforma eclesiástica, de manera que ya no podían los obispos resolver estos temas en forma reservada, sino que tenían que elevar al asunto a Roma para que la Santa Sede tomara cartas en el asunto. Luego de unos años, Benedicto XVI reconocerá "la vergüenza y el remordimiento que sentimos todos [en la Iglesia]" (2010, párr. 13) por casos como los descritos en la película.

El mismo Osservatore Romano, si bien más escuetamente, no considera anticatólica a Spotlight: "no es una película anticatólica, como se ha escrito, porque es capaz de dar voz al desánimo y el dolor profundo de los fieles ante el descubrimiento de estas terribles realidades" (Scaraffia, 2016, párr. 1). Es decir, da testimonio del desconcierto y dolor de los 
fieles por los graves errores cometidos en su Iglesia. Incluso, cree encontrar en ella un voto de confianza en el catolicismo:

El hecho de que de la ceremonia de los Óscares haya salido un llamamiento al Papa Francisco para que combata este flagelo debe ser visto como un signo positivo: hay aún confianza en la Institución, hay confianza en un Papa que está continuando la limpieza iniciada por su predecesor ya como cardenal. Hay aún confianza en una fe que lleva en su corazón la defensa de las víctimas, la protección de los inocentes. (Scaraffia, 2016, párr. 5)

El balance de la película es positivo, también para un católico, pues la erradicación del problema difícilmente se habría verificado sin la valiosa investigación de la que da testimonio con gran calidad artística. Fruto de esta investigación, su consecuencia directa, ha sido el necesario e improrrogable proceso de purificación que vivió la Iglesia norteamericana y está viviendo ahora la Iglesia universal. Pero siendo positivo, no es suficiente. Cuenta la verdad, pero no toda la verdad. Se precisa del esfuerzo crítico del espectador para completar el cuadro, pues si se queda solo con el final de la película, con las sombras, le habrán contado una historia verdadera con una conclusión falsa. 
SIGNOS

\section{Referencias}

Benedicto XVI. (2010). Carta pastoral del Santo Padre Benedicto XVI a los católicos de Irlanda. Recuperado de http://w2.vatican.va/content/benedict-xvi/es/letters/2010/ documents/hf_ben-xvi_let_20100319_church-ireland.html

Mark Ruffalo: “Tengo gran respeto por el periodismo”. (14 de febrero de 2016). La República. Recuperado de http://larepublica.pe/impresa/ocio-y-cultura/741151mark-ruffalo-tengo-gran-respeto-por-el-periodismo

Sánchez de la Nieta, A. (2016). Spotlight o lo que la Iglesia "le debe" al Boston Globe. Recuperado de http://conversacionescon.es/spotlight/

Scaraffia, L. (29 de febrero de 2016). Dos Óscares a "El caso Spotlight". L'osservatore Romano. Recuperado de http://www.osservatoreromano.va/es/news/dos-oscares-elcaso-spotlight 